\title{
Front Range Infrastructure Resources Project
}

\section{Project goal:}

To provide the public and decision makers with objective information about the location and characteristics of land, natural aggregate, water, and energy resources that are vital to sustaining an area and its infrastructure.

\section{What is the Front Range Infrastructure Resources project?}

Infrastructure construction and maintenance are critical to a community's vitality. Developing and maintaining the infrastructure, such as roads, buildings, and airports, require large amounts of three natural resources: aggregate (primarily crushed stone, sand, and gravel), water, and energy. As urban areas expand, local sources for these resources are depleted, and the resources become inaccessible or more costly to recover.

Between 1991 and 1997, Colorado was the Nation's fifth fastest growing State. Most of the new growth occurred along the Colorado Front Range, from the eastern foothills of the Rocky Mountains to the edge of the Great Plains. Rapid population growth has resulted in inadequate or deteriorating infrastructures in many Front Range communities. For example, because of local shortages, one-fifth of the construction aggregate used in building Denver International Airport had to be shipped approximately 100 miles from Wyoming. Aggregate costs were 16 to 20 percent of the total cost of this multibillion dollar construction project.

The U.S. Geological Survey's (USGS) Front Range Infrastructure Resources project (FRIRP) is a multidisciplinary research project that includes biologists, geologists, hydrologists, and geographers. The project is evaluating the region's infrastructure resources; it is

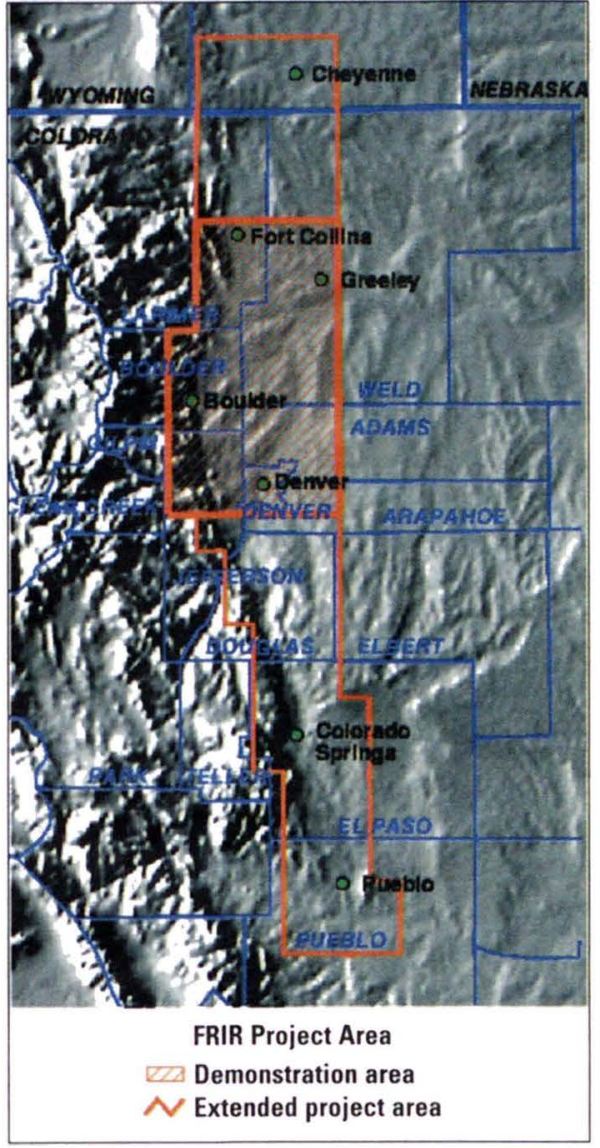

Figure 1. Project study area.

also identifying issues that may affect resource availability and providing decision-making tools to evaluate alternate methods for sustaining infrastructure resources. A regional inventory of aggregate, water, and energy resources will define the potential and limitations of these basic physical resources. Studies will relate resource inventories to resource models and availability, and will relate resource extraction to potential impacts on the environment. Geographic integration of data (geospatial databases) will provide an interactive tool to help stakeholders and collaborators in the Colorado Front Range make informed decisions.

The project, which began on October 1 , 1996, is now focused on a demonstration area in the northern Colorado Front
Range urban corridor. The demonstration area includes most of the Denver metropolitan area and the rapidly growing areas to the north in western Adams County, eastern Boulder County, southeastern Larimer County, and southwestern Weld County. Subsequent studies will expand the area to the entire Rocky Mountain Front Range urban corridor (from Cheyenne, Wyoming, to Pueblo, Colorado) (see fig. 1.) Project scientists interact closely with stake-holders and cooperators along the Front Range, including State and local agencies and producers and users of infrastructure resources, to ensure that the project focuses on the issues of the highest priority.

\section{What studies are included in the project?}

\section{Minerals}

Aggregate-sand, gravel, and crushed stone-is used in every aspect of building and maintaining an urban area. Aggregate is used in concrete for buildings, bridges, airports, and highways and in asphalt for highways. By the year 2000, Colorado will consume over 52 million tons of aggregate per year or more than 12 tons per person per year! As part of the FRIRP, the USGS is conducting studies to locate aggregate resources and determine the appropriate use for each resource.

The two primary sources of aggregate in Colorado are sand and gravel deposits along rivers or streams and certain types of bedrock found in the foothills and mountains. Models of sand and gravel deposits relate physical and compositional characteristics to resource quality and quantity and to potential impacts on natural systems from mining the deposits. Five characteristics help determine the most appropriate use for 
aggregate materials-hardness, strength, stability, durability, and chemistry. Is the aggregate material hard and resistant to breakdown from handling and abrasion? Is the material strong and able to withstand the weight of the load it must carry? Is the material sound and durable and resistant to wetting and drying, freezing and thawing? Finally, is the material chemically reactive? Some rocks are reactive when used in portland cement concrete; others have electrochemical properties that cause asphalt to adhere poorly to the aggregate.

USGS scientists are also documenting how construction, land use zoning, regulations, and citizen opposition to mining affect the availability of aggregate resources. They will examine factors that limit the availability of aggregate resources, such as quality, historic uses, competing land use, and environmental restrictions (fig. 2). Also, analyses of aggregate availability must take into account the specifications for use that determine the quality of aggregate required for particular jobs.

\section{Water}

Bedrock aquifers are a vital source of water for the Denver metropolitan area and much of eastern Colorado. Ground water is an infrastructure resource that is present in shallow aquifers and deeper bedrock aquifers in much of the demonstration area of the FRIRP. Mapping the area's ground water resources was undertaken in this project in cooperation with the Colorado Department of Natural Resource's Division of Water Resources and the Colorado Water Conservation Board.

The Laramie-Fox Hills aquifer, which extends through a 6,700-square-mile area of the Denver Basin (primarily to the north, east, and south of Denver) is the lowermost and largest of four bedrock aquifers in the basin. The four bedrock aquifers lie one on top of another much like a stack of pancakes, with the largest pancake on the bottom and the smallest pancake on the top. More drinking water is pumped from these aquifers by municipal and domestic wells than from any other aquifers in Colorado.

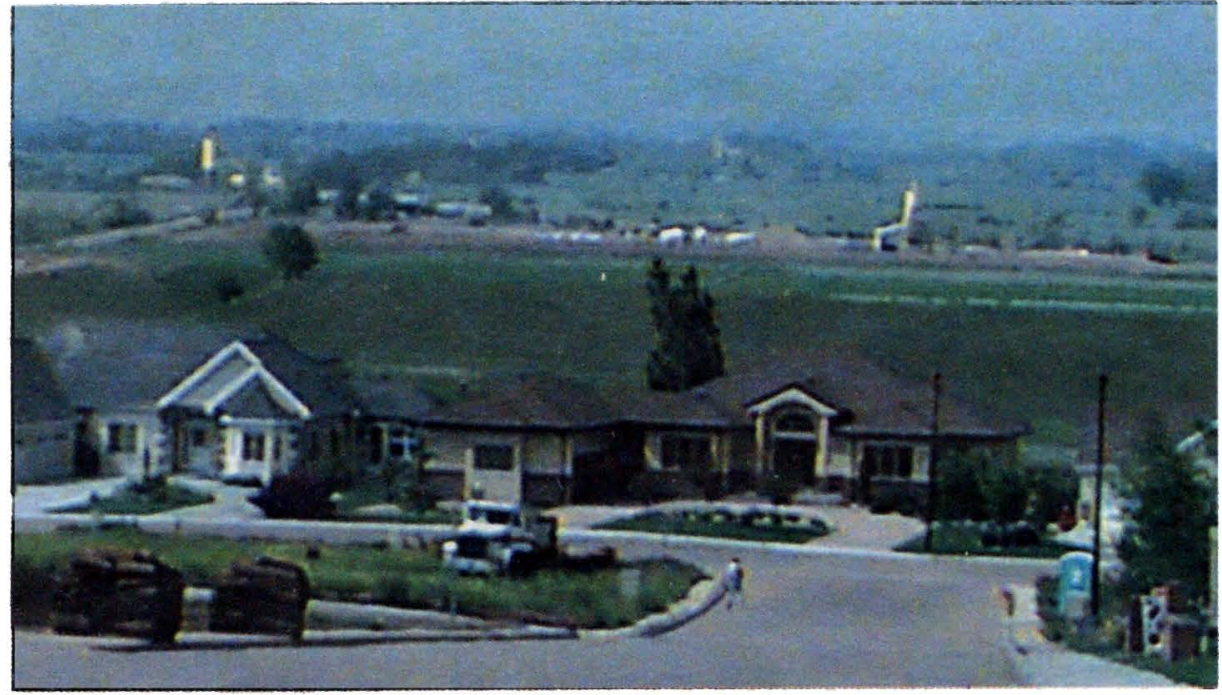

Figure 2. New residential development (foreground) adjacent to agriculture and gravel extraction (background).

An area west of Golden from Clear

Creek to the present-day Jefferson County Center is one of Colorado's earliest examples of the need for the type of information being produced by the FRIRP. In this small area during the late 1800's, urban growth in Golden was in conflict with the mining of energy (coal) and mineral (clay) resources, and the resulting land use (mining) affected biological resources by eliminating habitat and water resources by decreasing aquifer recharge. It is doubtful that planning for the development of infrastructure resources and urban areas was an important consideration in the late 1800 's. If it had been, perhaps the consequences of mining (scars, rubble) would not be as apparent 100 years later.

Development of one infrastructure resource sometimes conflicts with another infrastructure resource. For example, if aggregate is mined from the alluvium (sand and gravels deposited by the rivers), ground water flow in that part of the alluvial aquifer is disrupted. If the aquifer is protected and water is pumped from it, aggregate cannot be mined. In a few parts of the metropolitan area, the conflict between mining aggregate and retaining natural flow within the aquifer has been partly resolved by drilling water wells on berms between flooded gravel pits and pumping the ground water, which is readily replenished by water from the adjacent pits. This can be preferable to pumping directly from the pits because the ground water requires less treatment for human consumption. Thus, both mineral and water resources can be extracted with proper planning.

\section{Energy}

Much of the oil and gas used within the Front Range is extracted from the Wattenberg field, north of Denver (fig. 3). Gas and oil are extracted from sedimentary rocks that are deeply buried. The FRIRP is assessing the potential quantity of petroleum reserves, how faulting is affecting gas production, likely locations for future oil and gas development, and the impact of petroleum extraction on land use. The Wattenberg field has had intensive drilling in recent years. For example, in 1994, 80 percent of the wells drilled in Colorado were in the Wattenberg field, mostly in Weld County. Although there has been and will continue to be keen interest in the oil and gas resources of the region, urbanization occurring within the Front Range has already cut off some of the petroleum resources from future development. This is especially apparent in Greeley, which has banned drilling within the city limits.

Development of oil and gas resources can also conflict with the development of aggregate resources. Thousands of oil and gas wells already exist in the Front Range, and many of these wells were drilled in areas containing aggregate. Thus, any future development of aggregate will be restricted by the existence of oil and gas wells, which 


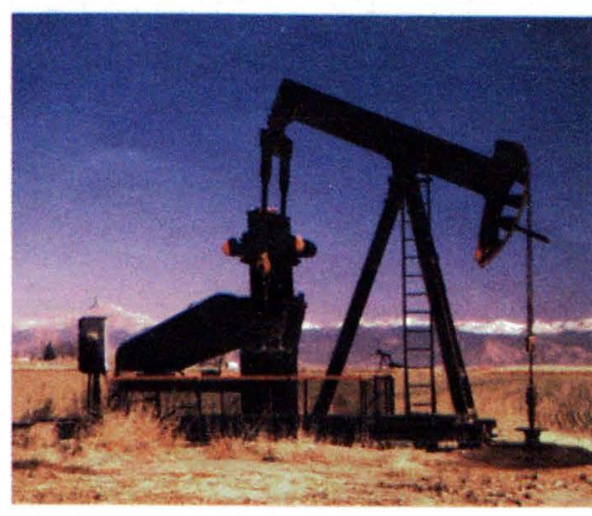

Figure 3. Gas well in Watttenberg field.

results in partial loss of one resource (for example, aggregate) by development of another (for example, oil and gas). Although coal is no longer mined in the study area, the USGS, in cooperation with the Colorado Geological Survey, is compiling digital files of the locations and depths of former coal mines.

\section{Biology}

Biological resources are of interest to the FRIRP because of potential conflicts with the development of energy, mineral, and water resources. Riparian (streamside) communities in particular are a focal point for conflicting societal demands. The cottonwoods, willows, and herbaceous understories making up these communities are structurally complex compared to the surrounding landscape and support diverse assemblages of mammals, birds, reptiles, and amphibians. However, riparian areas are also primary sites for water development, agriculture, grazing, sand and gravel mining, and recreation, each of which may preclude other uses. A species of particular interest in this regard is the Preble's meadow jumping mouse (fig. 4), which the Federal Government recently listed as threatened; the mouse lives primarily in heavily vegetated riparian habitats. Habitat loss and degradation caused by agricultural, residential, commercial, and industrial development are believed to imperil the continued existence of this species. The FRIRP, in cooperation with the Colorado Division of Wildlife, is investigating the habitat needs of the mouse and the potential for conflict with activities such as sand and gravel extraction. By better understanding the needs of the species, we may be able to classify habitats according to their potential to support the mouse, thus focusing concern in appropriate areas, and perhaps even develop reclamation techniques to benefit the species. The FRIRP is also investigating ways of restoring other riparian habitats and methods for controlling undesirable exotic species, such as salt cedar, that often invade these riparian communities.

\section{Land characterization}

People have a profound impact on the environment. Understanding the makeup of the landscape, how it has changed, and how it might continue to change is important in the urban environment. Urbanization, agricultural intensification, resource extraction, and water resource development are examples of humaninduced phenomena that have significant impact on people, the economy, and resources. The FRIRP is identifying those critical components that define the landscape and is investigating and developing models to characterize and describe the land and urban growth. The landscape of the United States is constantly changing. The types, timing, causes, extent, and impacts of change vary from place to place. Local changes in land use can have effects that ripple throughout a larger region.

The combined data resources of the project will yield credible and comprehensive insights into the character and impacts of land use change, insights that can contribute to balancing economic growth with environmental protection.

A temporal database documenting urban land transformation can be used by urban and regional planners, policy and decision makers, and earth scientists to measure trends in urban sprawl, analyze patterns of water pollution and sedimentation, understand the effects of development on ecosystems, and develop predictive modeling techniques to better forecast future areas of urban growth.

\section{Database development}

Essential for the project is temporally consistent database framework on which all the other layers generated by the project scientist will be placed. The existing base cartographic data for the

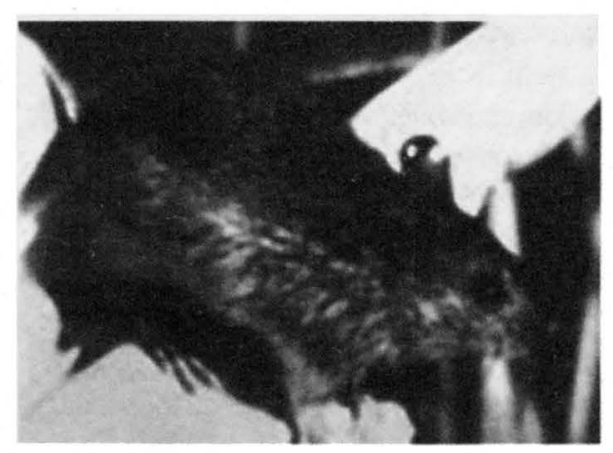

Figure 4. Preble's meadow jumping mouse.

study area range in time from the 1950's to the 1990's, which makes it difficult to portray the region accurately. The revision of the base cartographic layers (transportation networks, surface hydrography, administrative boundaries, manmade structures) will be done with 1996-97 images. The framework will also include data on elevation, slope, aspect, township and survey sections (Public Land Survey System), land use and land cover, soils, and geologic structure. Historical land use and land cover and major transportation network data layers (1930's, 1950's, 1970's) will be used to gain an understanding of the growth of the region and the past use of natural resources.

The USGS is preparing the project data in digital format so that it can be used in geographic information systems (GIS) and decision support systems to help planners make timely and informed decisions regarding future development.

\section{Decision support system}

Decisions regarding land and resources are complex and emotional, often resulting in charged debates and discussions. A traditional way to identify the site and create plans for landscape alteration is to diagram or map the proposed change. Although this is very helpful to decisionmakers, it does not often present the complete impact of the change. What is surrounding or underneath the area may not be taken into account nor clearly portrayed. Also, different parties have their own ideas and interpretations of change. To aid decision makers in this complex process, the FRIRP is developing a Group Spatial Decision Support System (GSDSS ). The system combines interactive meeting 
software with spatial data layers. The system incorporates the project's natural resource information with socioeconomic data from planning departments, and so on. In a group meeting, such as a planning board or citizens meeting, the GSDSS allows each member of the group to create and compare scenarios with those of other members. Assigning levels of importance to the different data layers is also possible. Each interactive scenario outlines a region of interest, such as a potential open-space park or single-family development. Using this region of interest and the collected data layers, the GSDSS determines overlaps and creates reports about natural and biological resources, as well as providing pertinent land characterization and socioeconomic information. Comparing and modifying these scenarios with group-defined priorities should help people with different interests reach a consensus.

\section{Information}

For more information on the project visit our web site at http://webserver.cr.usgs.gov/frirp/ FRIRP.htm

For more information on the individual aspects of the project contact any of the following:

Aggregate Resources:

Bill Langer

Phone: 303-236-1249

E-mail: blanger@usgs.gov

Biological Resources:

Butch Roelle

Phone: 970-226-9435

E-mail: butch_roelle@usgs.gov

Energy Resources:

Fishman

Phone: 303-236-1542

E-mail: nfishman@usgs.gov
Geographic Resources:

Carol Mladinich

Phone: 303-202-4313

E-mail: csmladinich@usgs.gov

Geologic Mapping:

David Moore

Phone: 303-236-1271

E-mail: dwmoore@usgs.gov

Geologic Remote Sensing:

Eric Livo

Phone: 303-236-1388

E-mail: elivo@usgs.gov

Geophysics:

Karl Ellefsen

Phone: 303-236-7032

E-mail: ellefsen@usgs.gov

Group Spatial Decision Support System:

Richard Zirbes

Phone: 303-202-4303

E-mail: rjzirbes@usgs.gov

Mineral Resources:

Dave Lindsey

Phone: 303-236-6482

E-mail: dlindsey@usgs.gov

Dan Knepper

Phone: 303-236-1385

E-mail: dknepper@usgs.gov

Minerals/Materials

Dave Wilburn

Phone: 303-236-8747 ext. 337

E-mail: Wilburn@usgs.gov

Water Resources:

Stan Robson

Phone: 303-236-4882 ext. 305

E-mail: srobson@usgs.gov
For information on other USGS products and services, call 1-800-USA-MAPS, use the EARTHFAX fax-on-demand system, which is available 24 hours a day at 703-648-4888, or visit the general interest publications Web site at http://mapping.usgs.gov/ www/products/mappubs.html.

Please visit the USGS home page at http://www.usgs.gov/. 